\title{
Interactive comment on "Synergy of the westerly winds and monsoons in lake evolution of global closed basins since the Last Glacial Maximum" by Yu Li and Yuxin Zhang
}

\section{Anonymous Referee \#1}

Received and published: 21 June 2020

General comments The study presents an interesting way of separate the influence of westerlies and monsoon on mid-latitude closed basins by complementing paleoclimates records and climate models. However, minor changes should be made before final publication. 1. Most of the work and its conclusions are applicable to the Northern Hemisphere $(\mathrm{NH})$; in my opinion this should be represented in the title of the work. 2 . In Material and Methods section, authors consider three periods (LGM, MH and PI); however, in most of the analyses only LGM and Holocene are studied, having only a few mentions about the late Holocene or PI period. 3. I am little confused, in P7, L144 said "Whereas, effective moisture increases since the LGM over the global Tropics". However, one the main conclusions of this work is that monsoon areas were charac-

Printer-friendly version

Discussion paper 
terized by dry conditions during the LGM (and late Holocene), and humid conditions during the early-mid Holocene. Please could you explain that? 4. Figure 2: What are the dark areas in the map? Letters $(a)$ and $(b)$ are missing. 5. Figures 3 and 4 : Improve figure caption, is not totally representative of the figure. 6. In P9, L177 text indicate that a moisture index was reconstructed from early Holocene to late Holocene. However, in methodology that fact is not totally explained.

Interactive comment

Specific comments 1. Figure 3: For reduce unnecessary information on Figure 3, only include latitude at one side of the map 2. Figure caption on figure 6 : I think that letters "(a)", "(b)" and "(c)" must go at the beginning of each description. 3. P4, L93, 96 and 100: It must be Equation (1) instead of Eq (2) 4. P4, L101: It must be Equation (2) instead of Eq. (3) 5. P13, L231: Text is confusing: "Major trend of moisture conditions revealed by the (...) is a gradual decrease since the early Holocene, and reaches the wettest status between 8 and $6 \mathrm{kyr}$ in the East Asian monsoon region". It describes a decrease in moisture but ends with wettest conditions. Please reword the sentence in order to avoid confusion.

Technical corrections P2, L50: "Simulate" instead of "simulating". Include (precipitation minus evaporation) after P-E P2, L51: delete space before Pre-Industrial P2, L51-58: The sentence is too long, needs to be rephrased. P2, L53: "which" instead of "where" P2, L57: add a "s" at the end of monsoon (= monsoons) P2, L58: "Last" instead of "last" (capital letter) P2, L58-61: I think that the phrase "(..) according to records of Quaternary ice sheets, low-mid latitudes summer insolation and winter insolation, $\delta 18$ O of Greenland ice core, etc." could be summarized.

P3, L67: delete space before 3 in CCSM3 P3, L69: delete space before 4 in CCSM4 P3, L84: Hostetler and Bartlein (1990)'s model

P4, L90: Add parenthesis to the referenced cited (= Morrill (2004) and Li and Morrill (2010)) P4, L94: Add a space after AB P4, L95: Add space before parenthesis "lake(m year-1)"

Printer-friendly version

Discussion paper 
P4, L104: Add parenthesis to the referenced cited (= Li and Morrill (2010)). Replace Eq. (2) by (1) and (3) by (2). P4, L108: Delete "and" and replace phrase "and lake CPD status information sorted by latitudes are shown in Table 2" by "Lake status information sorted by latitudes are shown in Table 2".

P6, Fig. 1: In figure caption replace "mm/year" by "mm year-1"

P7, L138: Replace "that lakes with" by "in which lakes with"or "where lakes with". It is not clear to me if Qinghai Lake, Hala Lake and Zhabuye are examples of lake with relative high-level during $\mathrm{MH}$ or PI. P7, L139: "and Zhabuye Lake..."

P9, Fig. 3: In figure caption add ", respectively." After "Wang et al. (2008)"

P10, L185: Add "that" before "a humid climate" P10, L186: Delete "And" at the beginning of the phrase P10, L187: Delete "the" before "paleoclimate modelling" P10, L188: Text is confusing, needs rewording "... resulting in the loss of lake water reduces and the high lake level sustains." P10, L190: replace "to increase" by "increasing"

P11, L201: include "and late Holocene" after "prevailed in the early Holocene".

Line 232: The phrase could be written as "The longest and highest-resolution drill core from Lake Qinghai (An et al. 2012) indicate that summer monsoon record generally $(\ldots)$

P14, L255: Change sentence by "In these regions, winter precipitation accounts for a large proportion of annual precipitation (Li et al., 2008)".

Interactive comment on Clim. Past Discuss., https://doi.org/10.5194/cp-2020-53, 2020.

Printer-friendly version

Discussion paper 